\title{
Statistical Evaluation of Stepwise Regression Method and Autoregressive Integrated Moving Average Method for Forecasting of Groundnut (Arachis hypogaea L.) Productivity in Junagadh District of Gujarat
}

\author{
K. Sathees Kumar ${ }^{1 *}$ and Mayur Shitap ${ }^{2}$ \\ ${ }^{1}$ Department of Agricultural Statistics, Bidhan Chandra Krishi Viswavidyalaya, \\ Mohanpur, Nadia741 252, West Bengal, India \\ ${ }^{2}$ Department of Agricultural Statistics, Junagadh Agricultural University, \\ Junagadh-362 001, Gujarat, India \\ *Corresponding author
}

\section{A B S T R A C T}

\begin{tabular}{|l|}
\hline K e y w o r d s \\
ARIMA, Stepwise \\
regression, Weather \\
indices
\end{tabular}

\section{Introduction}

Oilseeds play a significant role in Indian agriculture, as a second major crop (next to cereals) possessing $11 \%$ of the total cultivated area and devoted $9 \%$ production out of the total agricultural production. India oozed at the period of late 1990s as one of the world's largest edible oils importers and consumer of oilseeds and their products. The cash crops share about $6.87 \%$ GDP and oilseed crops share about $1.5 \%$ to agricultural GDP (Anon., 2017). Groundnut (Arachis hypogaea L.) is most imperatives oilseed crop among others. Our country is one of the world's premier producers having the largest area under groundnut in the globe.

For ensuring lucrative prices to the growers, not only requires improved crop technology for increasing the production but also need long term and short-term policy decision for yearly export and import. This naturally demands a believable and valid pre-harvest forecast of the production of crops. Multifarious methods are available for 
forecasting the crop productivity were stepwise regression method and ARIMA method used for profuse investigation and the forecasting the crop productivity. Earlier studies investigated to compare the forecasting performance of stepwise regression and ARIMA for forecasting of mango and banana productivity (Rathod and Mishra, 2018). When ARIMA applies better from stepwise regression, the current productivity is more dependent on the previous productivity than the weather parameters and vice versa. The present study emulated the above investigation to compare the ability of stepwise regression and ARIMA model for groundnut productivity forecasting in the Junagadh district of Gujarat.

\section{Materials and Methods}

\section{Data description}

Year wise data of groundnut productivity and historical weather data of groundnut growing season $\left(24^{\text {th }}\right.$ Standard Meteorological Week to $37^{\text {th }}$ Standard Meteorological Week) including maximum temperature (MAX T), Minimum temperature (MIN T), weekly total rainfall (RF), morning relative humidity $\left(\mathrm{RH}_{1}\right)$, afternoon relative humidity $\left(\mathrm{RH}_{2}\right)$ of Junagadh district of Gujarat for the years 1985 to 2015 were collected from Director of Agriculture and Agro-meteorology Cell, College of Agriculture, Junagadh Agricultural University, Junagadh, respectively.

The data from 1985 to 2009 used for analysis and the data from 2010 to 2015 were used for model validation by percent deviation. To seek the possibility of early forecasts before 6,4 , and 2 weeks of the harvest of groundnut crop, three models were fitted using generated weather variables for the period of $10\left(24^{\text {th }}\right.$ SMW to $\left.33^{\text {rd }} \mathrm{SMW}\right), 12\left(24^{\text {th }}\right.$ to $\left.35^{\text {th }} \mathrm{SMW}\right)$, and $14\left(24^{\text {th }}\right.$ to $37^{\text {th }}$ SMW $)$ weeks crop periods.

\section{Stepwise regression method}

In stepwise regression method, two approaches were developed based on using the explanatory variables.

Week-wise approach using original weather variables.

Weather indices using correlation as weight

Year-wise groundnut productivity data and weekly weather data were used for the above approaches and utilized for stepwise regression (Montgomery et al., 2003) to avoid the multicollinearity consequences.

\section{Week-wise approach using original weather variables}

In this approach, the weekly average data as per the original scale were used as the explanatory variables and time period was also considered as the explanatory variable (Draper and Smith, 1981).

The mathematical expression of this model is,

$\mathrm{Y}=\mathrm{A}_{0}+\sum_{i=1}^{\sum_{i=1}^{w} a_{i j} X_{i j}}+\mathrm{bT}+\mathrm{e}$

Where,

$\mathrm{Y}=$ Groundnut productivity of the Junagadh district (Kg/ha)

$\mathrm{A}_{0}=$ Constant

$\mathrm{X}_{\mathrm{ij}}=$ Observed value of $\mathrm{i}^{\text {th }}$ weather variable in $\mathrm{j}^{\text {th }}$ week, $i=1,2, \ldots \ldots, \mathrm{p}$ and $\mathrm{j}=1,2, \ldots$ $\ldots, \mathrm{w}(\mathrm{p}=5, \mathrm{w}=10,12$ and 14$)$

$\mathrm{T}=$ Year number includes correcting for long term upward or downward trend in productivity

$\mathrm{a}_{\mathrm{ij}}$ and $\mathrm{b}$ are partial regression coefficients associated with each $X_{i j}$ and time trend respectively.

$\mathrm{e}=$ Error term 
Weather indices using correlation as weight

This methodology proposed by the Indian Agricultural Statistical Research Institute (Agrawal et al., 1980), New Delhi, modified the IASRI model was used to convey how the crop productivity was affected by the weather variables as a function of the correlation coefficient between respective weather variables and the crop productivity. In this approach, two types of weather indices developed for getting the explanatory variables (First order weather indices and second order weather indices). First order weather indices $\left(\mathrm{Z}_{\mathrm{ij}}\right)$ were determined by each weather variables and second order weather indices $\left(\mathrm{Z}_{\mathrm{ii}} \mathrm{j}\right)$ were determined by the interaction of the weather variables (multiplication of two possible weekly weather variables).For first order weather indices, two possible indices were developed. One is unweighted weather indices (simple aggregation of weather variable which means the power of the correlation coefficient is zero) another one is weighted weather indices (power of correlation coefficient is one). Similarly, for second order indices, two kind indices (unweighted and weighted) were made by weekly products of weather variables. The time period was also considered as the explanatory variable.

$Y=A_{0}+\sum_{i=1}^{\mu} \sum_{j=0}^{1} a_{i j} z_{i j}+\sum_{i \neq i=1}^{\mu} \sum_{j=0}^{1} a_{i i j i} z_{i i j i}+b T+e$

Where,

$\mathrm{Y}=$ Groundnut productivity of the Junagadh district $(\mathrm{Kg} / \mathrm{ha})$

$\mathrm{A}_{0}=$ constant

$\mathrm{T}=$ Year number included correcting for long term upward or downward trend in productivity

$\mathrm{a}_{\mathrm{ij}}, \mathrm{a}_{\mathrm{ii}} \mathrm{j}$, and $\mathrm{b}$ are estimated partial regression coefficients associated with $\mathrm{z}_{\mathrm{ij}}, \mathrm{z}_{\mathrm{ii}} \mathrm{j}$, and time trend respectively.

$\mathrm{e}=$ Error term

$p=$ Number of weather variables

$\mathrm{Z}_{\mathrm{ij}}=\sum_{j=0}^{1} \sum_{w=1}^{m} \gamma_{\mathrm{i} w}^{j} x_{i w}$ and $\mathrm{Z}_{\mathrm{ii} \mathrm{j}}=$

$\sum_{j=0}^{1} \sum_{w=1}^{m} r_{i i n}^{j} x_{i W^{\prime}} x_{\tilde{i} w}$

Where,

$\mathrm{w}=$ weeks $(\mathrm{w}=1,2, \ldots \mathrm{m}=10,12$, and 14$)$

$\mathrm{m}=$ No. of weeks up to the time of the forecast

$\mathrm{X}_{\mathrm{iw}}=$ value of $\mathrm{i}^{\text {th }}$ weather variable at $\mathrm{w}^{\text {th }}$ week of groundnut growing season

$\mathrm{Z}_{\mathrm{ij}}$ and $\mathrm{Z}_{\mathrm{ii}} \mathrm{j}_{\mathrm{j}}$ are generated first order and second-order variables

$r_{i w}^{j}=$ correlation coefficient between the groundnut productivity and $\mathrm{i}^{\text {th }}$ weather variable at $\mathrm{w}^{\text {th }}$ period

$r_{i i w_{w}}^{j}=$ correlation coefficient between the groundnut productivity and the multiplication of $i^{\text {th }}$ and $i^{\text {th }}$ weather variables at $\mathrm{w}^{\text {th }}$ period

\section{Autoregressive Integrated Moving Average Model (ARIMA)}

An ARIMA model, time-series data of groundnut productivity data used for prediction purposes. Box-Jenkins time-series models i.e. ARIMA is known as "Univariate Box-Jenkins technique" (Box and Jenkins, 1976). This method is contrary to stepwise regression method which explains the relation between successive observation and previous observations of the successive observation. Univariate Box-Jenkins ARIMA (p, d, q) revealed as follows,

$\emptyset(B)(1-B)^{d} Y_{t}=\theta(B) \varepsilon_{t}$

Where,

$\emptyset(B)=1-\emptyset_{1} B-\emptyset_{2} B^{2} \ldots-\emptyset_{p} B^{p}$

(Autoregressive parameter) 
$\theta(B)=1-\theta_{1} B-\theta_{2} B^{2} \ldots-\theta_{p} B^{q}$

average parameter)

(Moving

$\varepsilon_{t^{-}}$Error term, d- degree of differencing to make a series of stationary, B - Backshift operator, i.e. $\mathrm{B}^{\mathrm{a}} \mathrm{Y}_{\mathrm{t}}=\mathrm{Y}_{\mathrm{t}-\mathrm{a}}$

The ARIMA model has three steps, viz. Identification, estimation and diagnostic checking. Identification of $\mathrm{d}$ is necessary to transform a nonstationary time series in to stationary. Testing of stationarity was employed by estimates of mean, autocovariance and autocorrelation of the data. Identification of $\mathrm{p}$ and $\mathrm{q}$ were decided by PACF's correlogram and ACF's correlogram respectively.

The estimation of parameters was calculated by the maximum likelihood technique. In diagnostic checking, the goodness of fit for the ARIMA model (Sarda and Prajneshu, 2002) were checked by Akaike's Information Criterion (AIC) and Schwartz-Bayesian Criterion (SBC) and testing of error independence were checked by Chi-square test (Ljung and Box, 1978). If the model is not satisfied with the above criteria, the above three stages are repeated until getting the satisfactory ARIMA model for forecasting.

\section{Comparison of MLR and ARIMA models}

Coefficient of determination $\left(\mathbf{R}^{2}\right)$

$R^{2}=1-\frac{\sum_{i=1}^{n}\left(Y_{i}-Y_{i}{ }^{\wedge}\right)^{2}}{\sum_{i=1}^{n}\left(Y_{i}-\bar{Y}\right)^{2}}$

Where $\mathrm{R}^{2}$ indicates the value of variation in the dependent variable accounted for due to the model.

$\mathrm{Y}_{\mathrm{i}}-$ Observed productivity

$\mathrm{Y}_{\mathrm{i}}^{\wedge}$-Estimated productivity

\section{Adjusted coefficient of determination ( )}

$\overline{\mathrm{R}}^{2}=1-\frac{(\mathrm{n}-1)\left(1-\mathrm{R}^{2}\right)}{(\mathrm{n}-\mathrm{k}-1)}$

Root Mean Square Error (RMSE)

$\operatorname{RMSE}=\left[\sum_{\mathrm{i}=1}^{\mathrm{n}}\left(\mathrm{Y}_{\mathrm{i}}-\hat{\mathrm{Y}}_{\mathrm{i}}\right)^{2} / \mathbf{n}\right]^{1 / 2}$

Mean Absolute Error (MAE)

$\mathrm{MAE}=\sum_{\mathrm{i}=1}^{\mathrm{n}}\left|\mathrm{Y}_{\mathbf{i}}-\hat{\mathbf{Y}}_{\mathbf{i}}\right| / \mathbf{n}$

The fitted models, which had higher values of $\mathrm{R}^{2}$ and with lower values of RMSE and MAE, were considered to be better.

\section{Test of forecasting values by using percent} deviation

Forecast values for remaining years by using selected models were tested based on percentages of forecasting error. Percentages of forecasting error were calculated as under

$\%$ of $\mathrm{PD}=\left(\frac{\mathrm{Y}-\hat{\mathrm{Y}}}{\mathrm{Y}}\right) \times 100$

Where PD is the percent deviation

$\mathrm{Y}$ is the observed value of the remaining years

$\hat{\mathrm{Y}}$ is the forecast value of the remaining years

\section{Results and Discussion}

\section{Week-wise approach using original weather variables}

In a fitted model using data for 10, 12 and 14 weeks crop period (Table 1), the set of explanatory variables entered in the equation consisted viz., $\quad \mathrm{X}_{59}$ (afternoon relative 
humidity of $9^{\text {th }}$ week), $\mathrm{X}_{44}$ (morning relative humidity of $4^{\text {th }}$ week), $X_{26}$ (minimum temperature of $6^{\text {th }}$ week) and $\mathrm{X}_{58}$ (afternoon relative humidity of $8^{\text {th }}$ week). These variables explained about $58.10 \%$ of the variation in productivity of groundnut. The results indicated that the partial regression coefficients of all included variables were positive and significant. The forecasted productivity of groundnut productivity for the fitted equation (Table 2) showed 8.66 to 53.50 percent deviation from observed productivity.

\section{Correlation coefficient as weight using generated weather variables}

The variables recorded in the model (Table 1) for 10 weeks data were $Z_{141}$ (weight of correlation coefficient to the product of maximum temperature and morning relative humidity), $\mathrm{Z}_{121}$ (weight of correlation coefficient to the product of maximum temperature and minimum temperature), $Z_{51}$ (weight of correlation coefficient of afternoon relative humidity), $\mathrm{Z}_{131}$ (weight of correlation coefficient to the product of maximum temperature and weekly total rainfall) and $Z_{31}$ (weight of correlation coefficient of rainfall) explained about $86.30 \%$ of the variation in the groundnut productivity.

The results referred that the partial regression coefficients of $Z_{141}, Z_{121}, Z_{51}$, and $Z_{131}$ were positive and significant, whereas, the partial regression coefficient of $Z_{31}$ was negative and significant. The deviations of actual productivity and forecasted productivity (Table 2) ranged between 12.95 to $15.72 \%$. The model (Table 1) for 12 weeks data comprised of only were $Z_{51}$ (weight of correlation coefficient of afternoon relative humidity) explaining about $52.60 \%$ of the variation in productivity of groundnut crop. The partial regression coefficient of $Z_{51}$ was positive and significant with the deviations of actual productivity and forecasted productivity (Table 2) ranging between 18.96 to $64.38 \%$. The variable entered in the model (Table 1) for 14 weeks data were $Z_{131}$ (weight of correlation coefficient to the product of maximum temperature and weekly total rainfall), $\quad Z_{241}$ (weight of correlation coefficient to the product of minimum temperature and morning relative humidity), $Z_{31}$ (weight of correlation coefficient of weekly total rainfall) and $Z_{11}$ (weight of correlation coefficient of maximum temperature) explained about $88.00 \%$ of the variation in productivity of groundnut crop.

The results mentioned that the partial regression coefficients of $Z_{131}, Z_{241}$, and $Z_{11}$ were positive and significant, whereas the partial regression coefficient of $Z_{31}$ was negative and significant. The deviations of actual productivity from forecasted productivity (Table 2) ranged from 11.82 to

$16.87 \%$. Looking to higher (88.00\%), lower deviations (11.82 to $16.87 \%$ ), RMSE (144.64) and MAE (116.51) in prediction, the model of 14 weeks could be considered as pre-harvest forecast model which can predict the productivity at 2 weeks before harvest with $\mathrm{R}^{2}$ value $90.60 \%$. The model for 10 weeks data has low deviations (12.95 to 15.72 $\%)$ as compared to the model of 14 weeks which can predict at 6 weeks before harvest. Also, there is no much difference in (86.30\%), RMSE (149.68) and MAE (119.41), model with10 weeks data as compared to a model of 14 weeks $\left(\overline{\mathrm{R}}^{2}=88.00 \%, \quad \mathrm{RMSE}=144.64 \quad\right.$ and $\mathrm{MAE}=116.51$ ).

In stepwise regression models, among the two approaches using correlation coefficient as weight approach gave the highest and lower RMSE, MAE and lower deviations than week-wise using original weather variable. So, the use of correlation coefficient as weight approach gave better performance for 
forecasting the groundnut productivity of Junagadh district. The present study was identical to the result of groundnut yield forecasting in Kolhapur, Maharashtra (Dhekale et al., 2014).

Table.1 Fitted Step-wise regression models

\begin{tabular}{|c|c|c|c|c|c|c|}
\hline APPROACHES & WEEKS & $\begin{array}{c}\text { STEPWISE } \\
\text { REGRESSION } \\
\text { EQUATIONS }\end{array}$ & $\mathbf{R}^{2}(\%)$ & $\overline{\mathbf{R}}^{2}(\%)$ & RMSE & MAE \\
\hline \multirow{3}{*}{$\begin{array}{c}\text { Correlation } \\
\text { coefficient as weight } \\
\text { using generated } \\
\text { weather variables }\end{array}$} & 10 & $\begin{array}{l}\mathrm{Y}=-3536.76+1.24 * \mathrm{Z}_{141} \\
+5.95 * \mathrm{Z}_{121}+15.27 * \\
\mathrm{Z}_{51}+1.37 * \mathrm{Z}_{131}-41.73^{*} \mathrm{Z}_{31}\end{array}$ & 89.90 & 86.30 & 149.68 & 119.41 \\
\hline & 12 & $Y=-2240.21+31.31 * Z_{51}$ & 55.10 & 52.60 & 316.21 & 245.43 \\
\hline & 14 & $\begin{array}{l}Y=-1301.31+1.08^{*} \\
Z_{131}+0.65^{*} Z_{241}-31.49^{*} \\
Z_{31}+100.79 * Z_{11}\end{array}$ & 90.60 & 88.00 & 144.64 & 116.51 \\
\hline \multirow{3}{*}{$\begin{array}{l}\text { Week-wise approach } \\
\text { using generated } \\
\text { weather variables }\end{array}$} & 10 & \multirow{3}{*}{$\begin{array}{l}\mathrm{Y}=10910.35+18.12 * \\
\mathrm{X}_{59}+43.97 * \mathrm{X}_{44}+231.71 * \\
\mathrm{X}_{26}+15.95 * \mathrm{X}_{58}\end{array}$} & \multirow[t]{3}{*}{66.90} & \multirow[t]{3}{*}{58.10} & \multirow[t]{3}{*}{271.32} & \multirow[t]{3}{*}{196.02} \\
\hline & 12 & & & & & \\
\hline & 14 & & & & & \\
\hline
\end{tabular}

Table.2 Forecasted productivity based on Step-wise regression and it's percent deviations from observed productivity

\begin{tabular}{|c|c|c|c|c|c|}
\hline Year & $\begin{array}{c}\text { Observed } \\
\text { Productivity } \\
\text { (Kg/ha) }\end{array}$ & \multicolumn{2}{|c|}{$\begin{array}{c}\text { Correlation coefficient as weight } \\
\text { using generated weather variables }\end{array}$} & $\begin{array}{c}\text { Week-wise approach } \\
\text { using generated } \\
\text { weather variables }\end{array}$ \\
\cline { 3 - 6 } & & $\mathbf{1 0}$ weeks & $\mathbf{1 2}$ weeks & $\mathbf{1 4}$ weeks & $\mathbf{1 0 , 1 2}$ and 14 weeks \\
\hline $\mathbf{2 0 1 0}$ & 2162 & 1882.03 & 1752.00 & 1888.07 & 1842.74 \\
& & $(12.95)$ & $(18.96)$ & $(12.67)$ & $(14.77)$ \\
\hline $\mathbf{2 0 1 1}$ & 1774 & 1524.27 & 1370.94 & 1564.23 & 1620.40 \\
& & $(14.08)$ & $(22.72)$ & $(11.82)$ & $(8.66)$ \\
\hline $\mathbf{2 0 1 3}$ & 3590 & 3025.65 & 1278.76 & 2984.28 & 1669.35 \\
& & $(15.72)$ & $(64.38)$ & $(16.87)$ & $(53.50)$ \\
\hline $\mathbf{2 0 1 4}$ & 3123 & 2693.49 & 1636.89 & 2739.19 & 1673.62 \\
& & $(13.75)$ & $(47.59)$ & $(12.29)$ & $(46.41)$ \\
\hline
\end{tabular}

Figures in parentheses indicate percent deviation of forecasted productivity from observed productivity (productivity of 2012 and 2015 are outliers) 
Table.3 Fitted ARIMA models

\begin{tabular}{|c|c|c|c|c|c|c|c|c|c|c|c|}
\hline ARIMA & $\mathrm{C}$ & $\operatorname{AR}\left(\Phi_{1}\right)$ & $\operatorname{MA}\left(\theta_{1}\right)$ & $\left.\mathbf{M A} \theta_{2}\right)$ & $\operatorname{MA}\left(\theta_{3}\right)$ & $\mathbf{R}^{2}(\%)$ & $\overline{\mathbf{R}}^{2}(\%)$ & RMSE & MAE & AIC & BIC \\
\hline$(0,1,1)$ & $\begin{array}{c}71.77 \\
(105.45)\end{array}$ & - & $\begin{array}{c}0.99 \\
(7.71)\end{array}$ & - & - & 69.30 & 58.80 & 544.92 & 430.38 & 13.04 & 13.10 \\
\hline$(0,1,2)$ & $\begin{array}{c}4.99 \\
(65.15)\end{array}$ & - & $\begin{array}{l}1.40 \\
(2.65)\end{array}$ & $\begin{array}{l}-0.42 \\
(0.95)\end{array}$ & - & 64.10 & 59.80 & 525.65 & 387.67 & 13.06 & 13.15 \\
\hline$(0,1,3)$ & $\begin{array}{c}93.11 \\
(94.69)\end{array}$ & - & $\begin{array}{c}1.29 \\
(2.63)\end{array}$ & $\begin{array}{l}-0.37 \\
(0.91)\end{array}$ & $\begin{array}{c}0.05 \\
(0.43)\end{array}$ & 63.30 & 56.50 & 549.58 & 402.95 & 13.35 & 13.39 \\
\hline$(1,1,1)$ & $\begin{array}{c}34.91 \\
(67.55)\end{array}$ & $\begin{array}{l}-0.40 \\
(0.28)\end{array}$ & $\begin{array}{c}1.00 \\
(14.59)\end{array}$ & - & - & 65.20 & 61.10 & 517.19 & 398.62 & 13.04 & 13.12 \\
\hline$(1,1,2)$ & $\begin{array}{c}32.30 \\
(80.82)\end{array}$ & $\begin{array}{l}-0.75 \\
(0.44)\end{array}$ & $\begin{array}{c}0.53 \\
(32.57)\end{array}$ & $\begin{array}{c}0.47 \\
(15.56)\end{array}$ & - & 65.70 & 59.30 & 531.42 & 391.16 & 13.27 & 13.33 \\
\hline$(1,1,3)$ & $\begin{array}{c}46.72 \\
(96.84)\end{array}$ & $\begin{array}{l}-0.75 \\
(1.03)\end{array}$ & $\begin{array}{c}0.60 \\
(40.24)\end{array}$ & $\begin{array}{c}0.49 \\
(15.23)\end{array}$ & $\begin{array}{l}-0.09 \\
(2.97)\end{array}$ & 66.10 & 57.10 & 548.53 & 392.06 & 13.49 & 13.54 \\
\hline
\end{tabular}

Table.4 Forecasted productivity based on ARIMA and it's percent deviations from observed productivity

\begin{tabular}{|c|c|c|c|c|c|c|c|c|}
\hline Year & $\begin{array}{c}\text { Observed } \\
\text { Productivity }\end{array}$ & \multicolumn{7}{|c|}{ ARIMA model } \\
\cline { 3 - 8 } & $\mathbf{( 1 , 1 , 1 )}$ & $\mathbf{( 0 , 1 , 2 )}$ & $\mathbf{( 0 , 1 , 3 )}$ & $\mathbf{( 1 , 1 , 1 )}$ & $\mathbf{( 1 , 1 , 2 )}$ & $\mathbf{( 1 , 1 , 3 )}$ \\
\hline $\mathbf{2 0 1 0}$ & 2162 & 1457 & 2077 & 1796 & 1941 & 1809 & 1796 \\
& & $(32.61)$ & $(3.93)$ & $(16.93)$ & $(10.22)$ & $(16.33)$ & $(16.93)$ \\
\hline $\mathbf{2 0 1 1}$ & 1774 & 1414 & 1795 & 1460 & 1525 & 1456 & 1460 \\
& & $(20.29)$ & $(-1.18)$ & $(17.70)$ & $(14.04)$ & $(17.93)$ & $(17.70)$ \\
\hline $\mathbf{2 0 1 3}$ & 3590 & 1365 & 1828 & 1628 & 1692 & 1714 & 1628 \\
& & $(61.98)$ & $(49.08)$ & $(54.65)$ & $(52.87)$ & $(52.26)$ & $(54.65)$ \\
\hline $\mathbf{2 0 1 4}$ & 3123 & 1312 & 1862 & 1470 & 1622 & 1511 & 1470 \\
& & $(57.99)$ & $(40.38)$ & $(52.93)$ & $(48.06)$ & $(51.62)$ & $(52.93)$ \\
\hline
\end{tabular}

Figures in parentheses indicate percent deviation of forecasted productivity from observed productivity (productivity of 2012 and 2015 are outliers)

Table.5 Comparison between the fitted Step-wise regression models and ARIMA model

\begin{tabular}{|l|c|c|c|c|}
\hline \multicolumn{1}{|c|}{ Methods } & $\mathbf{R}^{\mathbf{2}(\%)}$ & $\overline{\mathbf{R}}^{\mathbf{2}} \mathbf{( \% )}$ & $\mathbf{R M S E}$ & MAE \\
\hline $\begin{array}{l}\text { Regression model using the correlation } \\
\text { coefficient as the weight with generated } \\
\text { weather variables(model of 10 weeks) }\end{array}$ & 89.90 & 86.30 & 149.68 & 119.41 \\
\hline $\begin{array}{l}\text { Regression model using the week-wise } \\
\text { approach with original weather } \\
\text { variables(model of 10 weeks) }\end{array}$ & 66.90 & 58.10 & 271.32 & 196.02 \\
\hline ARIMA (1, 1, 1) & 65.20 & 61.10 & 517.19 & 398.62 \\
\hline
\end{tabular}


Fig.1 ACF and PACF of the groundnut productivity of Junagadh district
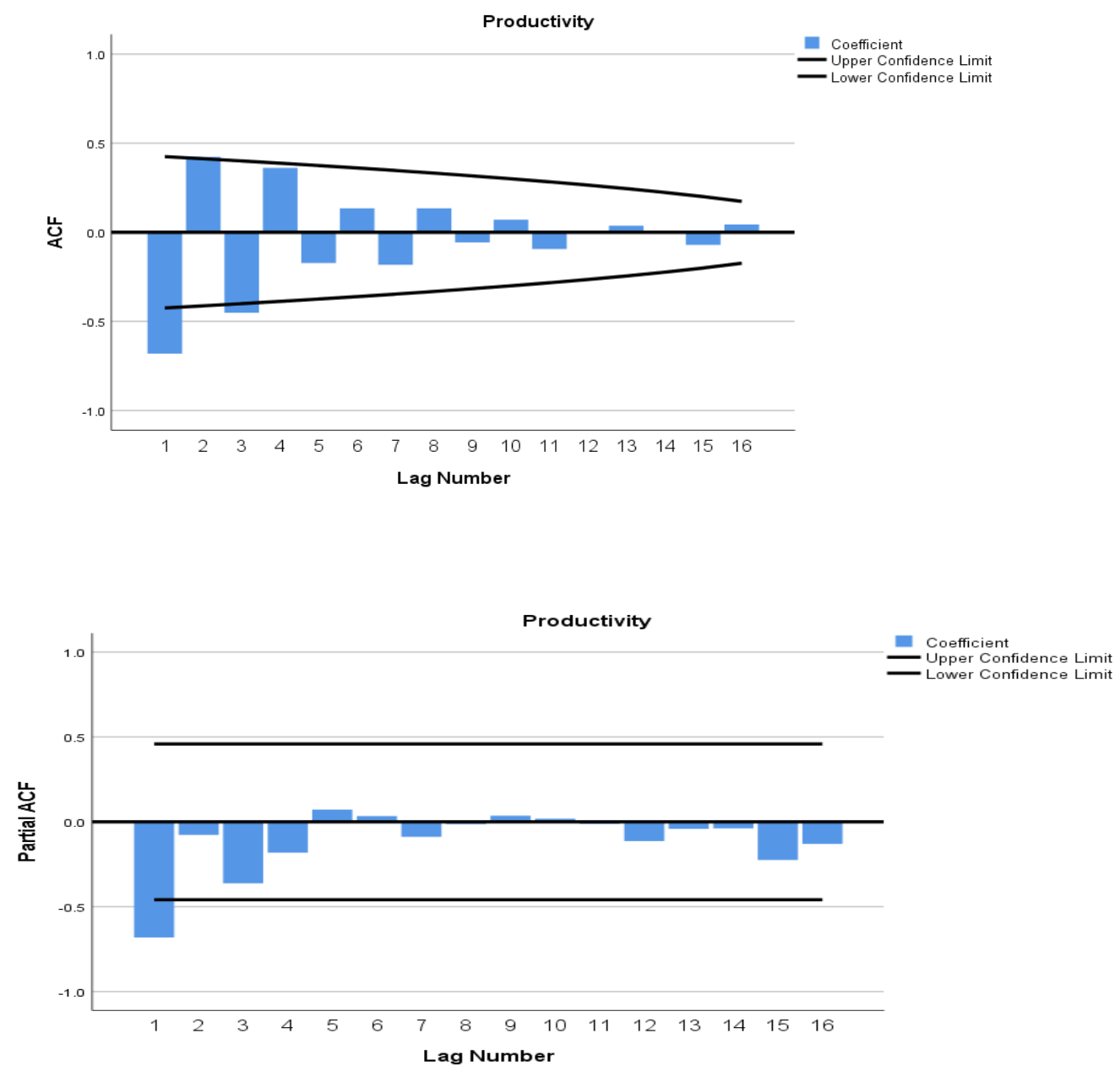

\section{Autoregressive Integrated Moving Average Model}

Time series data of groundnut productivity data was found as a non-stationary series. The new generated variable $X_{t}$ was made by taking the difference of one (i.e. $\mathrm{d}=1$ ) to make the series from non-stationary to stationary. The new series $X_{t}(d=1)$ was found to be stationary for groundnut productivity data. Partial autocorrelation function (PACF) and autocorrelation function (ACF) of various orders of $\mathrm{X}_{\mathrm{t}}$ was computed to identify the values of $p$ and $q$ respectively. The ACF $\left(\Upsilon_{k}\right)$ of the transformed variable was tail-off towards zero with cut off at third spike and
PACF $\left(\varphi_{\mathrm{kk}}\right)$ of the transformed variable tails off towards zero with cut off at first spike (Fig 1). This suggested that the algebraic family of ARIMA on $\mathrm{p}=0,1 \mathrm{~d}=1$, and $\mathrm{q}=0,1,2,3$ can be used. The results are given in Table 3 and forecasted productivity presented in Table 4. The assumptions of residuals i.e. independence of residuals were tested by Box-Ljung (Q) test indicated that all ARIMA models satisfied the assumption of residuals. Among the fitted models, $\operatorname{ARIMA}(1,1,1)$ model gave highest ${ }^{2}{ }^{2}(61.10 \%)$ and lowest RMSE (517.19), Whereas the lowest MAE (387.67) was observed in ARIMA $(0,1,2)$ and lowest BIC (13.10) was observed in ARIMA $(0,1,1)$ but ARIMA $(1,1,1)$ which 
gave highest $\overline{\mathrm{R}}^{2}$ and lowest RMSE had slightly greater MAE (398.62) and BIC (13.12) as compared to other models. The deviations of forecasted productivity from observed productivity was ranged from 10.22 to $52.87 \%$. The ARIMA $(1,1,1)$ was found to be best fitted model for forecasting the groundnut productivity in Junagadh district. The finding was contrary to Rajarathinam and Dixit (2007), they studied the groundnut yield trends in long-term fertilizer experiment at Junagadh.

\section{Comparison between the fitted Stepwise regression models and ARIMA model}

The comparison was made among these selected models and the fitted ARIMA models based on the coefficient determination $\left(\mathrm{R}^{2}\right)$, Adjusted coefficient of determination $\left(\overline{\mathrm{R}}^{2}\right)$, Root Mean Square Error (RMSE) and Mean Absolute Error (MAE). It is seen from the Table 5 that both the regression models viz., model using correlation coefficient as the weight with generated weather variables (10 weeks), and model using the week-wise approach with original weather variables $(10$ weeks) gave higher $\mathrm{R}^{2}(89.90 \%$ and $66.90 \%$, respectively), adjusted $\mathrm{R}^{2}$ (86.30\% and 58.10 $\%$, respectively) with lower RMSE (149.68 and 271.32, respectively), MAE (119.41 and 196.02, respectively) having lower per cent deviation between forecasted and observed productivity (12.95 to $15.72 \%$ and 8.66 to $53.50 \%$, respectively) as compared to ARIMA $(1,1,1)$ using 25 years data $\left(\mathrm{R}^{2}=\right.$ $65.20 \%, \overline{\mathrm{R}}^{2}=61.10 \%$, RMSE $=517.19$, MAE $=398.62$ and percent deviations $=10.22$ to $52.87 \%$ ). Stepwise regression had more potential than ARIMA for forecasting the groundnut productivity in Junagadh. Similar results were found, when forecasted the mango area and production in Karnataka region (Rathod and Mishra, 2017).
Based on the comparisons, the stepwise regression models performed better than the ARIMA models for forecasting the groundnut productivity in the Junagadh district of Gujarat. The study further identified that groundnut productivity was more influenced by weather parameters than previous records of groundnut productivity.

\section{References}

Agrawal, R., R. C. Jain, M. P. Jha and Singh, D. 1980. Forecasting of rice yield using climatic variables. Indian Journal of Agricultural Science, 50(9):680-684.

Anonymous. 2017. Division of Agricultural Economics, Indian Agricultural Research Institute, New Delhi. Available at http://www.iari.res.in>accessed $\quad 10$ august, 2019.

Box, G. E. P. and Jenkins, G. M. 1976. Time Series Analysis Forecasting and Control, Second Edition, Holden Day. PP: 88-122.

Draper, N.R. and Smith, H. 1981. Applied regression analysis, second edition, John Wiley and sons, New York.

Ljung, G. M and Box, G. E. P. 1978. On a Measure of Lack of fit in Time Series Models. Biometrika, 65: 297-303.

Dhekale, B. S., M. S. Sheraz, T. P. Dalvi, and Sawant, P. K. 2014. Forecast Models for Groundnut using Meteorological Variables in Kolhapur, Maharashtra. Journal of Agrometerology, 16 (2): 238-239.

Montgomery, D. C., E. A. Peck, and Vining G. G. 2003. Introduction to Linear Regression Analysis. John Wiley \& sons, Inc, PP: 221-258.

Sarda, C and Prajneshu. 2002. Modeling and Forecasting Country's Pesticide/ Consumption Data using ARIMA Time Series Approach. Annals of Agricultural Research, 23(4): 719-722. 
Rajarathinam, A and Dixit, S. K. 2007. Fitting of Groundnut Yield Trends in LongTerm Fertilizer Experiment- A TimeSeries Model Approach. Crop Research, 34: 92-96.

Rathod, S and Mishra, G.C. 2017. Weather Based Modeling for Forecasting Area and Production of Mango in Karnataka. International Journal of Agriculture,
Environment and Biotechnology, 10(1):149-162.

Rathod, S and Mishra, G.C. 2018. Statistical Models for Forecasting Mango and Banana Yield of Karnataka, India. Journal of Agricultural Science and Technology, 20: 803-816.

\section{How to cite this article:}

Sathees Kumar, K. and Mayur Shitap. 2020. Statistical Evaluation of Stepwise Regression Method and Autoregressive Integrated Moving Average Method for Forecasting of Groundnut (Arachis hypogaea L.) Productivity in Junagadh District of Gujarat. Int.J.Curr.Microbiol.App.Sci. 9(11): 84-93. doi: https://doi.org/10.20546/ijcmas.2020.911.009 